\title{
Phytochemical and Pharmacological Evaluation of Methanolic Leaf Extract of Piper methysticum
}

\author{
Nusrat Jahan $^{1}$, Sirajum Monira ${ }^{1}$, Seba Khondokar Orna ${ }^{1}$ and Amir Hossain ${ }^{2}$ \\ ${ }^{1}$ Department of Pharmacy, ASA University Bangladesh, Dhaka-1207, Bangladesh \\ ${ }^{2}$ Department of Pharmacy, Dhaka International University, Dhaka-1213, Bangladesh
}

(Received: June 10, 2021; Accepted: January 25, 2022; Published (web): January 29, 2022)

\begin{abstract}
Piper methysticum G. Forst., commonly known as Kava, is a dioecious perennial herb which is traditionally an important medicinal plant. The plant is used to treat fever, respiratory diseases, seizures, and urogenital problems. The present study was designed to evaluate the antioxidant, cytotoxic, membrane stabilizing and analgesic potential of methanol extract of Piper methysticum leaf. Phytochemical screenings of the crude extract revealed the occurrence of acidic compounds, alkaloids, glycosides, reducing sugars, gums, flavonoids, and combined reducing sugars. During antioxidant activity test, the total phenolic content of methanol extract was $42.66 \mathrm{mg}$ gallic acid equivalent/100 g extract and it displayed the $\mathrm{IC}_{50}$ value of $6.59 \mu \mathrm{g} / \mathrm{ml}$ to remove DPPH free radicals as compared to the standard butylated hydroxyl toluene $\left(\mathrm{IC}_{50}=6.38 \mu \mathrm{g} / \mathrm{ml}\right.$ ). The extract showed cytotoxicity against brine shrimp nauplii with an $\mathrm{LC}_{50}$ of $60.94 \mu \mathrm{g} / \mathrm{ml}$. Moreover, the test extract was found to be effective for stabilizing erythrocyte membrane against hypotonic solution induced hemolysis. The extract exhibited dose-dependent pain-relieving activity in mice. At doses of $250-$ and $500-\mathrm{mg} / \mathrm{kg}$ body weight, the plant sample revealed $26.92 \%$ and $37.95 \%$ of reduction in pain sensation induced by acetic acid, respectively when compared to the standard diclofenac-Na (54.81\%). The above results suggest that the selected plant extract possesses antioxidant, cytotoxic, membrane stabilizing and analgesic activities.
\end{abstract}

Key words: Piper methysticum, antioxidant, cytotoxic, membrane stabilizing, analgesic.

\section{Introduction}

Medicinal plants are crucial source of medicines performing an essential starring role in the health sector around the globe, as well as in the development of human health and the prevention and treatment of diseases. Medicinal plants are only used to treat diseases, but also as a potential material for maintaining good health. Different studies have shown that minimum two-third of the total residents worldwide hinge on herbal remedies for basic healthiness due to their few side effects (Islam et al., 2015).

Piper methysticum (Family: Piperaceae) is a member of the pepper family and locally familiar as kava, ava, awa. The plant is native to Africa,
Antarctica and the temperate zones of Asia. It has a glossy dark green leaf in the shape of a heart (Orwa et al., 2009). This plant is used in traditional medicine, for example to treat fever, respiratory problems, seizures, genitourinary system problems (Wang et al., 2015). Antioxidant is a substance that can prevent or inhibit oxidation and slow down the damage caused by free radicals to biological systems. Medicinal plants contain a variety of natural antioxidants such as carotenoids and phenolic compounds that can protect the integrity of body and metabolism (Angerhofer et al., 2009). Since the extract prevents the lysis of red blood cells caused by the hypotonic solution and heat, the plant may contain bioactive components having anti-

Corresponding author: Amir Hossain; Phone: +880 1715 646476; Email:hellotoamir@gmail.com

DOI: https://doi.org/10.3329/bpj.v25i1.57843 
inflammatory potential. An analgesic is an agent that acts on the central or peripheral sensory nervous system to reduce or eliminate pain without significantly changing consciousness.

Due to lack of sufficient information about the pharmacological properties of Piper methysticum, the present study was designed to determine antioxidant, cytotoxic, membrane stabilizing and analgesic activity of this plant species.

\section{Materials and Methods}

Sample collection and preparation: Leaves of $P$. methysticum were collected from Shariatpur District, Bangladesh. The plant was identified in Bangladesh National Herbarium (Voucher test number: DACB 47907). After thorough washing and drying, the leaves are ground into coarse powder, and then soaked in about $1.5 \mathrm{~L}$ of methanol for about 8 days. The mixture was filtered with Whatman filter paper number 1. Finally, $2.05 \%$ yield of the crude extract was obtained.

Drugs and reagents: Sodium carbonate, potassium dichromate, Folin Ciocalteu reagent, gallic acid (GA), butylated hydroxytoluene (BHT), aluminum chloride $\left(\mathrm{AlCl}_{3}\right)$, sulfuric acid $\left(\mathrm{H}_{2} \mathrm{SO}_{4}\right)$, nitric acid $\left(\mathrm{HNO}_{3}\right)$, sodium hydroxide, dimethyl sulfoxide (DMSO), ethylenediaminetetraacetic acid (EDTA), Na-nitrite, Tween-80, and ferric chloride $\left(\mathrm{FeCl}_{3}\right)$ were obtained from Sigma Chemical Co. In addition, castor oil was supplied from the local market. Moreover, aspirin, ibuprofen and diclofenac$\mathrm{Na}$ were bought from Square Pharmaceuticals Ltd.

Phytochemical screening: The crude extract was subjected to various chemical tests (Ghani, 2003) to determine the classes of compounds present in the extract.

Determination of DPPH free radical scavenging activity: The antioxidant potential was evaluated by DPPH (2,2-diphenyl-1-picrylhydrazyl) free-radical scavenging analysis (Blois 1958; Mahaldar et al., 2020). About $3 \mathrm{ml} 0.004 \%$ (w/v) ethanolic solution of the reagent was mixed with $1.0 \mathrm{ml}$ crude extract with proper shaking and was kept in the dark for about 30 min. Lastly, the absorbance was recorded at $517 \mathrm{~nm}$ using a UV-Vis spectrometer.

Quantification of total phenolic compounds: The total phenolic compounds in the test sample was determined by using the Folin Ciocalteu reagent (Velioglu et al., 1998; Sumi et al., 2021). Here, gallic acid was used as the standard.

Determination of cytotoxic activity: Cytotoxic activity was assessed utilizing brine shrimp lethality bioassay (McLaughlin et al., 1998), where the $\mathrm{LC}_{50}$ (50\% of lethal concentration) was computed using probit analysis software (LdP Line, USA) (Meyer et al., 1982; Bakr 2007).

Determination of erythrocytes membrane stabilizing activity: This method was first developed to examine the membrane stabilizing activity of plant extractives using erythrocytes (Shinde et al., 1999). Shortly, $5 \mathrm{ml}$ healthy human blood was collected and centrifuged to collect blood cells. The collected cells were then treated with hypotonic solution to induce hemolysis. On the other hand, two sets of test tubes containing blood cells were kept in water bath $\left(54^{\circ} \mathrm{C}\right)$ and ice bath $\left(5^{\circ} \mathrm{C}\right)$ for about $20 \mathrm{~min}$ to see the heat induced hemolysis.

Evaluation of peripheral analgesic activity: Peripheral analgesic activity was conducted by acetic acid-induced writhing assay (koster et al., 1959; Hossain et al., 2016). Briefly, the young albino mice were treated by standard diclofenac-Na and the plant extract in two groups ( 250 and $500 \mathrm{mg} / \mathrm{kg}$ dose). In addition, intraperitoneal administration of acetic acid was applied to provoke pain sensation in mice.

Evaluation of central analgesic activity: The central analgesic activity was evaluated by tail flick test in mice (Hossain et al., 2019; D'Amour and Smith 1941). In this method, a noxious stimulus in different group of mice is produced by tail immersion in hot water and the response by flicking of tail is measured.

Statistical assessment: Data were expressed as mean \pm SEM. The level of significance of each investigational results was calculated by correlation analysis, using the test $(\mathrm{p}<0.05)$. Additionally, 
Microsoft Excel 2016 was also used for arithmetical and graphical evaluation.

\section{Result and Discussion}

Phytochemical screening: In the present study, acidic compounds, alkaloids, glycosides, reducing sugars, gums, flavonoids, and combined reducing sugars were found in the methanol extract of $P$. methysticum leaf. The result of phytochemical screening was presented in Table 1.
$D P P H$ free radical scavenging potential: In this study, the plant extract showed strong antioxidant potential with $\mathrm{IC}_{50}$ (inhibitory concentration) value of $6.59 \mu \mathrm{g} / \mathrm{ml}$ as compared to $6.38 \mu \mathrm{g} / \mathrm{ml}$ exhibited by the standard BHT (Figure 1). Plant extracts containing polyphenolic components such as flavonoids, phenolic acids, and tannins etc. are well reported to have antioxidant property (Prakash et al., 2009).

Table 1. Results of phytochemicals screenings of $P$. methysticum extract.

\begin{tabular}{llc}
\hline Test Name & Phytochemical & Result \\
\hline Fehling's and Benedict's solution test & Reducing sugar & + \\
Fehling's solution test & Combined reducing sugar & + \\
Tannin test by $\mathrm{FeCl}_{3}, \mathrm{~K}_{2} \mathrm{Cr}_{2} \mathrm{O}_{7}$ solution & Tannins & - \\
Flavonoid test by conc. $\mathrm{H}_{2} \mathrm{SO}_{4}$ & Flavonoids & + \\
Test for saponins by distilled water & Saponin & - \\
Molisch's test & Gums & + \\
Steroid test by $\mathrm{H}_{2} \mathrm{SO}_{4}$ & Steroids & - \\
Mayer's and Dragendroff's test & Alkaloids & + \\
Test for glycoside by NaOH & Glycoside & + \\
Protein test by nitric acid & Proteins & - \\
Tests for acidic compounds by $\mathrm{NaHCO}_{3}$ & Acidic compounds & + \\
\hline
\end{tabular}

$(+)=$ present $;(-)=$ absent

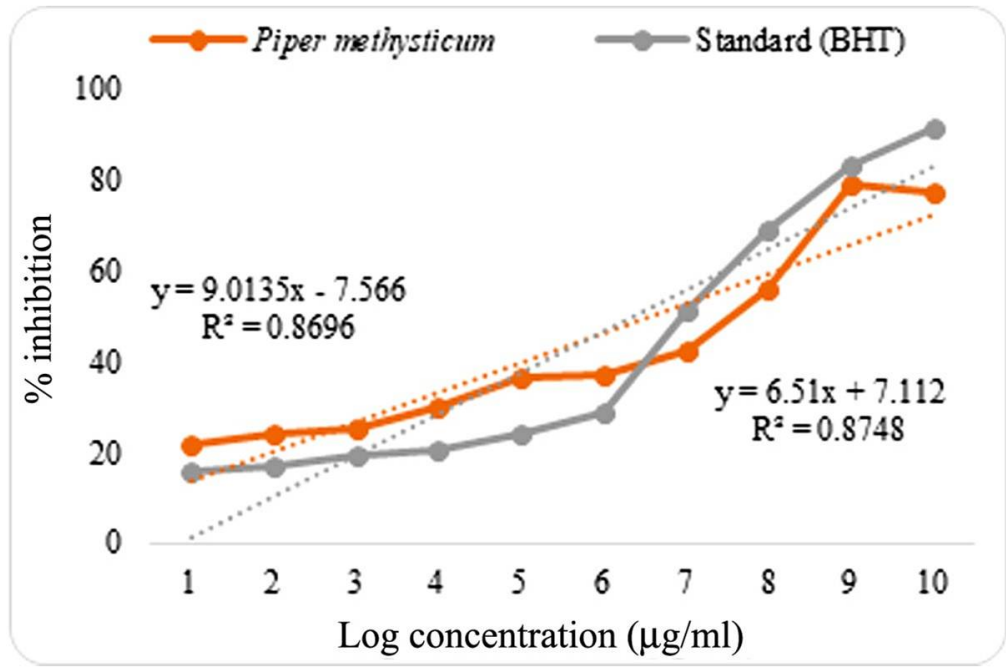

Figure 1. DPPH scavenging activity of P. methysticum and standard BHT (butylated hydroxytoluene). 
Total phenol content: Total phenolic content was $142.93 \mathrm{mg}$ gallic acid equivalent/ $100 \mathrm{~g}$ of dried extract (Figure 2). Such positive affiliation among phenolics and antioxidant potential is due to the capacity of compounds containing phenolic hydroxyl groups to scavenge the free radicals (Wang et al., 2007) which confirmed that antioxidants have the capacity of ruling over efficient proton donor or electron acceptor (Vinson et al., 2011).
Cytotoxic potentiality: In this bioassay, the plant extract showed significant cytotoxic activity against brine shrimp nauplii with $\mathrm{LD}_{50}$ of $60.94 \mu \mathrm{g} / \mathrm{ml}$, compared to that of standard vincristine sulfate $\left(\mathrm{LD}_{50}\right.$ $=1.73 \mu \mathrm{g} / \mathrm{ml}$ ). Medicinal plants with natural saponins, flavonoids have a spacious range of pharmacological potentialities like antiviral, cytotoxic, and anti-cancer activity (Ksouri et al., 2009; Das et al., 2011). For this bioassay, if the $\mathrm{LC}_{50}$ value becomes smaller than $1000 \mu \mathrm{g} / \mathrm{ml}$ are deemed bioactive (Martin-Cordero et al., 1995).

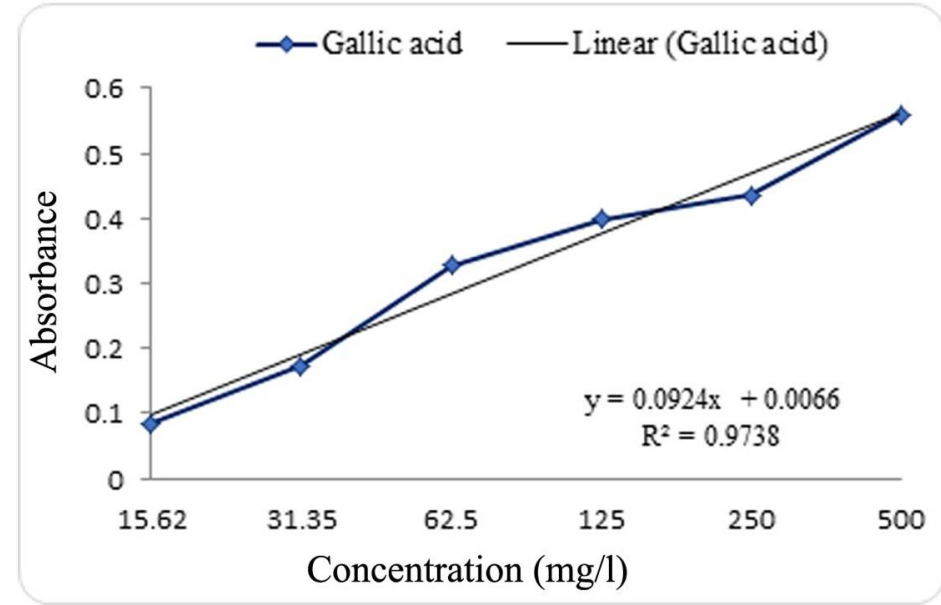

Figure 2. Total phenolic content of $P$. methysticum by gallic acid standard calibration curve.
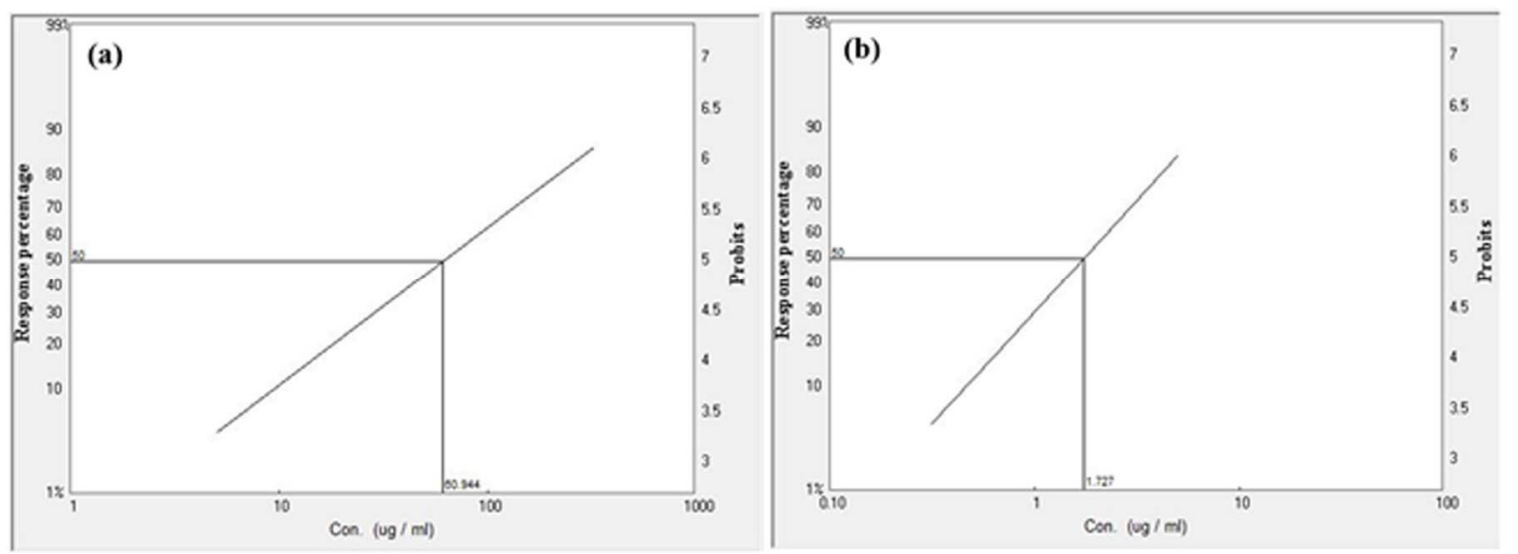

Figure 3. Brine shrimp lethality bioassay and $\mathrm{LD}_{50}$ for P. methysticum (a) and Standard (b).

However, it has been testified that there is somewhat association between cytotoxic potentiality and brine shrimp lethality assay where sample extract demonstrated a very decent level of mortality in inconsistency of nauplii which requires additional cell line test to assess cytotoxicity in further sensitive means (Saji et al., 2010; Ara et al., 1999). 
In membrane stabilizing activity test, the methanol extract of $P$. methysticum inhibited $91.71 \%$ and $87.50 \%$ hemolysis of RBC induced by hypotonic solution whereas standard acetyl salicylic acid showed 92.79\% inhibition (Table 2). The test sample also displayed $92.2 \%$ and $23.15 \%$ inhibition of hemolysis of RBC induced by heat as compared to the standard acetyl salicylic acid (96.34\% inhibition)

(Table 3).
Peripheral analgesic activity: The pain-relieving potentiality of the extract was confirmed by significant suppression of the acetic acid-induced writhing sensation by $26.92 \%$ and $37.5 \%$ at the dose of $250-$ and $500-\mathrm{mg} / \mathrm{kg}$ b.w., respectively. Here, the standard diclofenac sodium $(25 \mathrm{mg} / \mathrm{kg}$ b.w.) revealed $54.80 \%$ pain reduction (Table 3 ).

Table 2. Membrane stabilizing activity of $P$. methysticum extract on RBC membrane.

\begin{tabular}{llcc}
\hline \multirow{2}{*}{ Sample code } & Concentration & \multicolumn{2}{c}{$\%$ Inhibition of hemolysis } \\
\cline { 3 - 3 } & & & Hypotonic solution \\
\hline Hypotonic medium & $50 \mathrm{~mm}$ & 92.79 & 96.34 \\
Acetyl salicylic acid & $0.1 \mathrm{mg} / \mathrm{ml}$ & 91.71 & 92.20 \\
$P$. methysticum extract & $1.0 \mathrm{mg} / \mathrm{ml}$ & 87.50 & 23.15 \\
$P$. methysticum extract & $0.5 \mathrm{mg} / \mathrm{ml}$ & & \\
\hline
\end{tabular}

Table 3. Peripheral analgesic activity of $P$. methysticum extract in acetic acid-induced pain model.

\begin{tabular}{lccc}
\hline Treatment $(\mathrm{n}=5)$ & Dose $(\mathrm{mg} / \mathrm{kg})$ & Mean writhes & \% Inhibition \\
\hline Control (1\% Tween-80) & -- & $10.40 \pm 1.29$ & -- \\
Diclofenac sodium & 25 & $5.4 \pm 1.02 *$ & 54.81 \\
P. methysticum extract 250 & 250 & $7.60 \pm 2.00 * * *$ & 26.92 \\
P. methysticum extract 500 & 500 & $6.50 \pm 1.32 * *$ & 37.95 \\
\hline
\end{tabular}

Values are conveyed as mean $\pm \mathrm{SEM}, \mathrm{SEM}=$ Standard error for mean. $n=$ number of mice $(5), * \mathrm{P}=0.001, * * * \mathrm{P}=0.200$ and $* * \mathrm{P}=0.01$ vs. control.

Table 4. Central analgesic activity of $P$. methysticum extract in tail flick test.

\begin{tabular}{lcccccc}
\hline \multirow{2}{*}{ Treatment $(\mathrm{n}=5)$} & \multicolumn{5}{c}{ Period of inactivity of tail flick reaction in $(\mathrm{sec})$ at different time breaks } \\
& Basal & $30 \mathrm{~min}$ & $1 \mathrm{~h}$ & $2 \mathrm{~h}$ & 3h & $4 \mathrm{~h}$ \\
\hline Control $(10 \mathrm{ml} / \mathrm{kg})$ & $4.20 \pm 0.47$ & $4.30 \pm 0.33$ & $4.23 \pm 0.24$ & $4.08 \pm 0.52$ & $4.45 \pm 0.41$ & $4.27 \pm 0.16$ \\
Ibuprofen $(100 \mathrm{mg} / \mathrm{kg})$ & $2.90 \pm 0.18$ & $3.00 \pm 0.50$ & $2.92 \pm 0.21$ & $3.35 \pm 0.66$ & $2.80 \pm 0.34$ & $2.57 \pm 0.24$ \\
Test extract $(500 \mathrm{mg} / \mathrm{kg})$ & $2.52 \pm 0.22$ & $2.51 \pm 0.35$ & $1.96 \pm 0.37$ & $2.06 \pm 0.28$ & $2.29 \pm 0.52$ & $2.02 \pm 0.29$ \\
Test extract $(250 \mathrm{mg} / \mathrm{kg})$ & $1.88 \pm 0.09$ & $2.29 \pm 0.28$ & $2.49 \pm 0.32$ & $1.59 \pm 0.16$ & $2.08 \pm 0.28$ & $1.88 \pm 0.23$ \\
\hline
\end{tabular}

Results are conveyed as mean $\pm \mathrm{SEM}, \mathrm{SEM}=$ Standard error for mean.

Tail flick test: Administration of the plant extracts and standard ibuprofen significantly increased the pain elongation time in mice (Table 4). Plants containing antioxidant and analgesic properties have an ability to cure various health risk diseases that are harmful for body (Hossain et al., 2012; Barua et al., 2011). By the intraperitoneal administration of acetic acid, ache sensations are induced (Barua et al., 2011) while triggering the chemo-sensitive nociceptors are formed writhing reflex in experimental animals (Onasanwo et al., 2006). The inflammatory response with pain sensations is exemplified by acetic acid stimulated writhing models whereas the amount of analgesia was shown 
as percentage decline in a minimum quantity of gut shrinking (Machioro et al., 2005). Phytochemicals such as flavonoids with analgesic activity which is increasing the endogenic serotonin concentration or relate in conjunction with 5-HT2A and 5-HT3 receptors (Annegowda et al., 2010). In this existing study, the sample extract showed significant level of pain reduction which is comparable to the standard ibuprofen.

\section{Conclusion}

The present study indicates that the methanol extract of $P$. methysticum leaf contains phytochemicals capable of exerting antioxidant, cytotoxic, anti-inflammatory and analgesic potentials. However, more broad investigations are mandatory to isolate the bioactive compounds and find out the mechanisms related to these bioactivities.

\section{Acknowledgements}

The authors are grateful to Dept. of Pharmacy, ASA University Bangladesh and State University of Bangladesh (SUB) for providing necessary instrumental and other supports. We are also thankful to the Director, Bangladesh National Herbarium, Dhaka-1216, Bangladesh.

\section{References}

Angerhofer, C.K., Maes, D. and Giacomoni, P.U. 2009. The use of natural compounds and botanicals in the development of anti-aging skin care products. Skin Aging Handbook, pp. 205-263.

Annegowda, H.V., Mordi, M.N., Ramanathan, S. and Mansor, S.M. 2010. Analgesic and antioxidant properties of ethanolic extract of Terminalia catappa L. leaves. Int. J. Pharmacol. 6, 910-915.

Ara, J., Sultana, V., Ehteshamul-Haque, S., Qasim, R. and Ahmad, V.U. 1999. Cytotoxic activity of marine macro-algae on Artemia salina (Brine shrimp). Phytother. Res. 13, 304-307.

Bakr, E.M. 2007. LdP Line® http://www.ehabsoft. com/ldpline/

Barua, C.C., Buragohain, B., Roy, J.D., Talukdar, A., Barua, A.G., Borah, P. and Lahon, L.C. 2011. Evaluation of analgesic activity of hydroethanol extract of Plantago erosa Ex Roxb. Pharmacol. 2, 8695.

Blois, M.S. 1958. Antioxidant determinations by the use of a stable free-radical. Nature. 181, 1199-1200.

D'Amour, F.E. and Smith, D.L. 1941. A method for determining loss of pain sensation. J. Pharmacol. Exp. Ther. 72, 74-79

Das, J., Mannan, A., Rahman, M.M., Dinar, M.A., Uddin, M.E., Khan, I.N., Habib, M.R. and Hasan, N. 2011. Chloroform and ethanol extract of Spondias pinnata and its different pharmacological activity likeantioxidant, cytotoxic, antibacterial potential and phytochemical screening through in-vitro method. Int J. Res. Pharma. Biomed. Sci. 2, 1805-1812.

Ghani, A. 2003. Medicinal Plants of Bangladesh. 2nd edition. Dhaka: The Asiatic Society of Bangladesh, p. 603.

Hossain, A., Hossain, A. and Mannan, S.J. 2019. Evaluation of antioxidant and analgesic activities of three medicinal plants. Pharmacogn. Res. 11, 248253.

Hossain, H., Shahid-Ud-Daula, A.F.M., Jahan, I.A., Nimmi, I., Hasan, K. and Haq, M.M. 2012. Evaluation of antinociceptive and antioxidant potential from the leaves of Spilanthes paniculata growing in Bangladesh. Int. J. Pharm. Phytopharmacol. Res. 1, 178-186.

Islam, F., Hossain, A., Hossain, M.G., Murshid, G.M.M. and Rahman, M.M. 2015. Evaluation of antioxidant, analgesic and cytotoxic activities of Typha angustata L. root. Dhaka Univ. J. Pharm. Sci. 14, 55-59.

Koster, R., Anderson, M. and De Beer, J. 1959. Acetic acid for analgesic screening. Federation Proceedings, 18, 412-417.

Ksouri, R., Falleh, H., Megdiche, W., Trabelsi, N., Mhamdi, B., Chaieb, K., Bakrouf, A., Magné, C. and Abdelly, C. 2009. Antioxidant and antimicrobial activities of the edible medicinal halophyte Tamarix gallica $L$. and related polyphenolic constituents. Food Chem. Toxicol. 47, 2083-2091.

Mahaldar, K., Hossain, A., Islam, F., Islam, S., Islam, M.A., Shahriar, M. and Rahman, M.M. 2020. Antioxidant and hepatoprotective activity of Piper retrofractum against paracetamol-induced hepatotoxicity in Sprague-Dawley rat. Nat. Prod. Res. 34, 3219-3225.

Marchioro, M., Blank, M.D.F.A., Mourao, R.H.V. and Antoniolli, A.R. 2005. Anti-nociceptive activity of the aqueous extract of Erythrina velutina leaves. Fitoterapia, 76, 637-642. 
Martin-Cordero, C., Saenz, M.T., Ayuso, M.J. and Caviedes, M.A. 1995. Cytotoxic activity of Retama sphaerocarpa. Fitoterapia (Milano), 66, 495-498.

Meyer, B.N., Ferrigni, N.R., Putnam, J.E., Jacobsen, L.B., Nichols, D.E. and McLaughlin, J.L. 1982. Brine shrimp: A convenient general bioassay for active plant constituents. Planta Med. 45, 31-34.

Onasanwo, S.A. and Elegbe, R.A. 2006. Antinociceptive and anti-inflammatory properties of the leaf extract of Hedranthera barteri in rats and mice. African J. Biomed. Res. 2, 109-118.

Orwa, C., Mutua, A., Kindt, R., Jamnadass, R. and Simons, A. 2009. Agroforestree database: a tree reference and selection guide. Version 4.

Prakash, O., Kumar, R., Mishra, A. and Gupta, R. 2009. Artocarpus heterophyllus (Jackfruit): an overview. Pharmacogn. Rev. 3, 353-358.

Saji, A., Eimanifar, A., Soorae, P.S., Al Dhaheri, S., Li, W., Wang, P.Z. and Asem, A. 2019. Phylogenetic analysis of exotic invasive species of the brine shrimp Artemia Leach, 1819 (Branchiopoda, Anostraca) in Al Wathba Wetland Reserve (UAE; Abu Dhabi). Crustaceana. 92, 495-503.

Shinde, U.A., Phadke, A.S., Nair, A.M., Mungantiwar, A.A., Dikshit, V.J. and Saraf, M.N. 1999. Membrane stabilizing activity-a possible mechanism of action for the anti-inflammatory activity of Cedrus deodara wood oil. Fitoterapia, 70, 251-257.
Sumi, S.A., Siraj, M.A., Hossain, A., Mia, M.S., Afrin, S. and Rahman, M.M. 2021. Pharmacological activities of Ficus racemosa and analysis of its major bioactive polyphenols by HPLC-DAD. Evid. Based Complement Alternat. Med. 2016:3874516.

Velioglu, Y.S., Mazza, L., Gao, G. and Oomah B.D. 1998. Antioxidant activity and total phenolics in selected fruits, vegetables, and grain products. J. Agric. Food Chem. 46, 4113-4117.

Vinson, J.A., Su, X., Zibik, L. and Bose, P. 2001. Phenol antioxidant quantity and quality in foods: fruits. $J$. Agric. Food Chem. 49, 5315-21.

Wang, J., Qu, W., Bittenbender, H.C. and Li, Q.X. 2015. Kavalactone content and chemotype of kava beverages prepared from roots and rhizomes of Isa and Mahakea varieties and extraction efficiency of kavalactones using different solvents. J. Food Sci. Technol. 52, 1164-1169.

Wang, K.J., Yang, C.R. and Zhang, Y.J. 2007. Phenolic antioxidants from Chinese toon (fresh young leaves and shoots of Toona sinensis). Food chem. 101, 365371. 